\title{
"When coercion moves into your home" - A qualitative study of patient experiences with Outpatient Commitment in Norway
}

Henriette Riley, postgraduate student ${ }^{1}$, Georg Høyer, Professor/PhD/MD², Geir F. Lorem, Associate Professor/PhD ${ }^{3}$

Author Note

1. Department of Community Medicine, Faculty of Health Sciences, University of Troms $\emptyset$, Troms $\varnothing$, Norway and Division of General Psychiatry, University Hospital of North Norway, Tromsø.

2. Norwegian Research Network on Coercion in Mental Health Care and Department of Community Medicine, Faculty of Health Sciences, University of Troms $\varnothing$, Troms $\emptyset$, Norway.

3. Department of Health and Care Sciences, Faculty of Health Sciences, University of Troms $\varnothing$, Troms $\varnothing$, Norway.

\section{Corresponding Author}

Henriette Riley, Department of Community Medicine, University of Troms $\emptyset$ and Division of General Psychiatry, University Hospital of North Norway, Troms $\varnothing 9037$, Norway. Email: Henriette.riley@uit.no 


\begin{abstract}
The use of coercion on people with mental illness is a serious intervention, and a reduction in its use is a declared goal in mental health care. Yet many countries have introduced expanded powers of coercion in recent years, including outpatient commitment (OC). However, the evidence of the effectiveness of OC is inconclusive, and little is known about how patients experience OC schemes. The objective of this qualitative study was to explore (1) patients' experiences with OC, and (2) how routines in care and health services affect patients' everyday living. The data was collected in 2011-2012 and included 11 qualitative in-depth interviews with patients subject to OC. The study used a narrative approach to interviews, and a thematic narrative analysis. Participants generally complied with the OC requirements because of the clear and secure framework of OC, but also because they believed the alternative would be involuntary hospitalisation. No one reported physical force, but the coercion was experienced as limitation of freedom of action through excessive control and little patient influence or participation in their own treatment. Factors affecting patients' freedom of action under OC should be taken into account when the imposition of an OC order is considered.
\end{abstract}

Key words: coercion, community treatment orders, mental health, outpatient commitment, patient experiences.

\title{
What is known about this topic
}

- Most studies on outpatient commitment have examined the efficacy of such orders on treatment compliance and on the use of health care services. The findings have thus far been contradictory and inconclusive.

- Only two studies conducted in 2006 and 2011 were included in two Cochrane reviews on outpatient commitment in 2006 and 2011. The conclusion was that outpatient commitment may not be an effective alternative to standard care.

- Few studies have looked into the daily regime of patients under outpatient commitment orders and how patients experience the power of outpatient commitment.

\section{What this paper adds}

- Patients are ambivalent in their opinions on outpatient commitment Health care services are often experienced as more restrictive than the coercive powers of the $\mathrm{OC}$ order would suggest.

- The patients generally comply with the $\mathrm{OC}$ requirements, since the alternative is involuntary hospitalisation but also because the quality of everyday life is better than in inpatient care. 


\section{Introduction}

The use of coercion on mental health care patients constitutes an exception to the principle that health care is voluntary and based on consent. Coercion is generally unwelcome to patients (Ridley \& Hunter 2013) and often has a negative influence on the therapeutic alliance and perception of care and health services (Theodoridou et al. 2012). The use of coercion is a serious intervention in the patient's life, and it is therefore a declared international goal to reduce its use (World Health Organization 1996, Council of Europe 2004, Norwegian Directorate of Health 2010).

Nevertheless, in recent decades there has been an expansion of legal authority to exercise coercion on mental health patients in many countries, including the option for patients to be under coercion without being detained in hospital. The use of coercion in community care has expanded over recent years. Such schemes exist in at least 75 jurisdictions worldwide, and have different forms and names such as community treatment order, compulsory community care and outpatient commitment (Rugkåsa 2011). These names describe similar legal statutes authorising various coercive measures applying to patients living in the community, and the names can be used interchangeably. All schemes have in common that they make treatment adherence a condition for the patient to remain in the community and not to be hospitalised (Rugkåsa 2011 p 57). In this article we use the term Outpatient Commitment (OC).

Outpatient commitment is intended to be a less restrictive measure for patients who otherwise would be involuntarily hospitalised (Norwegian Directorate of Health 2010). Yet there is limited knowledge on both the outcome of OC, the factual use of coercion of patients subjected to OC, and how the coercive framework of such orders influences the patient's everyday lives (Churchill et al. 2007, Burns et al. 2013). It is therefore difficult to ascertain whether the service functions according to its intention. The aim of the present study was to explore how $\mathrm{OC}$ affects the patients' everyday lives, and how being on an OC order affects their perceived degree of freedom.

The use of OC appears to be increasing in many countries. In Sweden and in England and Wales, OC was found to be used considerably more frequently than expected (Swedish National Board of Health and Welfare 2009, CQC 2011, Rugkåsa 2011). The coercive powers of different $\mathrm{OC}$ schemes vary, such as an order to maintain contact with the treatment services or de-institutionalised coercive treatment (Høyer \& Ferris 2001, Burns \& Dawson 2009).

Outpatient commitment has been used in Norway since 1961 in that patients discharged from coercive treatment as inpatients could be recalled to hospital by force. In an amendment from 1999, the scheme was expanded to include the possibility of implementing OC for patients without prior hospitalisation. In Norway, the OC scheme is restricted to ensuring that the patient's contact with the treatment facility is maintained, but does not stipulate coercive measures to implement treatment refused by the patient. A specific treatment order is required to give 
medical treatment to a patient who refuses it. The intention is to ensure that the patient continues the treatment while living at home, this being a less invasive solution (Norwegian Department of Health and Social Affairs 1998). A prerequisite for $\mathrm{OC}$ is that the patient has a suitable place to live. In Norway, the precise extent of the use of OC is unknown, but according to the latest official figures from 2009, onethird of involuntarily admitted patients were discharged with an OC order (Norwegian Directorate of Health 2010).

Coercion is difficult to define, in regards to its use outside institutions. It ranges from the specific use of physical force, which is easy to observe, to more covert variants such as submitting to various rules or the will of others (Wertheimer 1993, Nyttingnes \& Husum 2011). Moreover, there are unclear boundaries between what may be considered coercion, threats, pressure, persuasion and advice, which contributes to the problem of defining coercion. Violation of personal integrity and autonomy are usually closely related to coercion, and its use is often criticised on this basis. Beauchamp \& Childress (2009) state that "Personal autonomy encompasses, at a minimum, self-rule that is free from both controlling interference by others and from certain limitations such as an inadequate understanding that prevents meaningful choice (p. 99)." Coercion is thus described as the outer limit of autonomy. The dilemma arises when patients are unable to look after themselves but do not want help. The subjective experience of coercion also varies greatly, with a surprisingly weak correlation between what patients are actually subjected to and their experience of the coercion involved (Hoge et al. 1997, McKenna et al. 1999, Iversen et al. 2007).

The justification for the use of coercion requires an assumption that the patient would actually have a better life with a coercive intervention than without it. Coercion in order to provide necessary medical care can thus be justified when patients are unable to take care of themselves. In such situations, coercion may have legitimacy in that it protects the patient's fundamental right to life and health. However, the use of coercion is subject to it being in the patient's best interest and exercised with a minimum of restriction on the patient's freedom (Szmukler \& Holloway 2000). Where the burden for the patient is greater than the positive outcome of the treatment, the use of coercion will be problematic. This represents a classic utilitarian argument of the least possible suffering for the fewest people (Mill 1972).

\section{Methods}

\section{Design}

This study used a narrative approach (Frank 2010). Narrative methods are appropriate for enhancing our understanding of social phenomena (Riessman 2008), and are suitable to gain an understanding of how people create identity and meaning, and how they organise and relate to past experiences (Raffard et al. 2010). Each participant has his or her unique history, and the purpose was to bring forth 
detailed descriptions of everyday life under OC by means of interviews. Participants were encouraged to talk about their experiences with OC to provide insights into how individuals perceive OC and how it affects their everyday life.

\section{Participants}

Eleven participants were recruited for the interviews, 7 men and 4 women aged 2360 years. Inclusion criteria were all patients under an OC order who had been at least under the order for three months and lived in the catchment area. Exclusion criteria were obvious language barriers and lack of capacity to consent. From information obtained from the hospital records altogether 109 persons fulfilled the inclusion criteria. The sample was reached through the lists of all OC patients treated at the University Hospital of North Norway. The selection of patients asked to participate was based on strategic selection, where variation in age, sex and place of residence was sought. To ensure variation in place of residence, three lists with names of potential interviewees were made according to the area where they lived. The first name on one of the list was picked as the first person to be asked for an interview. The next person was recruited from the next list, taking other strategic variables, like sex and age into account, and so on. When a name was selected according to the criteria above, the person was approached by a mental health worker in the community, either when they had an appointment as outpatients or by phone. Participants also received written information from the mental health worker, and returned the form of consent directly to the interviewer (Henriette Riley). Twenty-seven persons were asked to participate, 15 declined or did not respond and one person was excluded because she lacked capacity to consent. The interviews were preliminarily analysed after each interview, and we regarded a sample size of 11 patients to be sufficient to answer the study's research question.

The participants varied in their level of functioning. Six lived in private or council flats without staffing, and five in council flats with 24-hour supervision. There was also considerable variation in frequency of monitoring by clinicians, ranging from once a fortnight to continuous supervision. Their initial contact with mental health services varied between 3 and 40 years ago. All had diagnoses in the F20 group in ICD-10 (schizophrenia, schizotypal and delusional disorders). Two participants also had alcohol or drug problems. Outpatient commitment was arranged for all participants at discharge from involuntary hospitalisation.

\section{Data collection}

The data was developed in two stages. First the topic guide was compiled with the help of one focus group interview with three participants who had experience of both hospitalisation and OC. It took place at the hospital where the participants had been patients. The focus group interview was recorded, transcribed and researcher's notes by the first author were added. The focus group was the essential method for developing and revising the topic guide. The participants in the focus group were not included in the individual interviews. The focus group interview with users ensured the relevance of the topic guide, but also offered an overview of 
user experiences with OC. The discussions in the focus group and the research team enabled us to develop the five topic areas with underlying questions to be covered during the interviews: 1) Own experience of being under $O C$, 2) Content of the treatment, 3) Self-determination, 4) Specific examples of coercion, and 5) Awareness and understanding.

Once the topic guide was developed and revised, consenting participants were interviewed. Participants chose the interview location, three taking place at the University of Troms $\emptyset$ and the remainder in their homes. The interviews lasted from 30-120 minutes and were audiorecorded and transcribed. Notes were taken during and immediately after the interviews.

The interviews were conducted while the participants were under OC to be as close to the experience as possible. What concerns the patients and what they reveal about themselves, their situation and their suffering are all important to understand their experiences, needs and vital goals (Lorem 2008). The situational picture they choose to present can be understood in light of what matters to them and what they care about (Vitz 1990), and our aim has been to give a voice to people with firsthand knowledge of how OC is experienced and practised.

\section{Analysis}

We used a thematic narrative analysis. This method is particularly suitable for developing theoretical arguments, and invites the reader to think beyond the obvious in the text, creating space for interpretation (Riessman 2008). (i) Each interview was transcribed and first read separately to provide a general overview and holistic perspective of the narratives. Immediate impressions and thoughts were noted down. (ii)The next step was to create a thematic overview. For each interview, smaller units of meaning were extracted in the stories and coded to provide an overview and find common themes in the material. (iii) The third step was to perform an internal validation to ascertain what really lay behind the stories revealed by the analysis. This consisted in teasing out confirmations and contrasts in the material by bringing concepts from the initial analysis back to the text. (iv) The final step was an external validation where the findings were discussed in light of other research and theory. All authors participated in all stages of the analysis. The analysis resulted in three main themes (Figure. 1).

\section{FIGURE 1 here.}

\section{Ethical considerations}

The study was approved by the Regional Committee for Medical and Health Research Ethics of Northern Norway and supported by the management of the Mental Health Division at the University Hospital of North Norway. All participants, including the participants in the focus group, gave written consent before being interviewed. Patients were informed of the study orally and in writing and it was strongly emphasised that participation was voluntary. It was also made clear that they could withdraw at any stage if they no longer wished to participate, without 
giving a reason and without any negative consequences for the health care offered to them. All names are pseudonyms and personally identifiable data has been avoided.

\title{
Findings
}

\section{Being hospitalised}

When participants talked about their experience of OC, they compared it with experiences of hospitalisation. These stories typically reveal specific forms of coercion in connection with involuntary hospitalisation, for some also involving the police and forced medication. Several mentioned having been exposed to belts, physical restraint and seclusion, or of having witnessed such incidents. The stories generally reveal repeated use of coercive measures. Mari recounted a powerful and painful experience when forcibly medicated:

\footnotetext{
"In the beginning when I was admitted I was stuffed full of drugs without any reason given. (...) I've read in my record that I got big doses, I reacted very strongly to that. I was just lying down in bed and could hardly lift myself up. I had a flaming red flush under my skin, my ears were ringing, and I couldn't breathe through my nose. (...) It was just ... excuse the expression, bloody hell, to say it straight. (...) I was lying like that for a few days, could hardly eat. I remember having a really good appetite but I couldn't, it was like I was somehow paralyzed as if I was in an operation. (...) I felt like a guinea pig they were testing their medicines on."
}

Mari experienced strong side effects from the treatment and a loss of control; over her own body. Because of this experience, she is now strongly opposed to medicines.

The participants found that coercion often occurs unpredictably, as when Kari recalled an involuntary admission situation:

\begin{abstract}
"The police and a psychiatric nurse came in (the shop where I worked), I realised immediately they were up to something. They were investigating, they came in and bought things so they could see how I was. When I locked the door and wanted to leave, the police came. They'd been standing there keeping an eye on me, and came and took me when I was locking up. They drove me to the medical centre. It was so embarrassing! I thought it was horrible. (...) no one asked me (at the medical centre), I wasn't asked. I just got a lot of medicines and then I was sent by ambulance plane to hospital. (...) (in the hospital) ... they pushed me down on the bed, five people. They held me down to give me an injection."
\end{abstract}

The experience of humiliation and being deprived of any form of autonomy is strongly present in Kari's story. First she experienced stigmatisation in her small village by being taken away from her job by uniformed police and then she lacked any influence on subsequent events. Regardless of the intentions of the clinicians and police, Kari felt it humiliating to completely lose her autonomy.

Participants mentioned a lack of treatment choices and that coercive measures are not necessarily appropriate. It was perceived as meaningless to be subjected to coercion when they did not feel that coercion helped them to recover. Tone told of being admitted to compulsory observation, which involves temporary involuntary hospitalisation for up to 10 days: 
"(...) I had contact with so many staff who hardly spoke to me all the time they were on duty. Then I felt: 'Yes, well, this isn't much of an observation.' So I felt the coercion was there, but they didn't do what they were supposed to."

\section{Being at home}

The participants' perceptions of OC were ambivalent. One positive aspect is that being on $\mathrm{OC}$ was associated with having a place to live, closer follow-up and other social benefits. Having a home is precondition for $\mathrm{OC}$ and life has therefore improved, and patients preferred it to being hospitalised. Marius was very happy with his own council flat and the freedom it entailed:

\footnotetext{
"The best thing about my life now is my flat. I'm going to make it look nice, get some pictures on the walls, a ceiling fan and mats on the floor. I did the cleaning here yesterday, but I don't really know how well I did it."
}

During hospitalisation, the participants experienced having to follow rules and procedures, and having their own home was described as a positive contrast. Another benefit of OC mentioned here were more stable relationships with clinicians. One's own home and stable relations made life more predictable than the hospitalisation experiences. Mari described this contrast:

\footnotetext{
" (describing hospitalisation) .. another doctor suddenly came and said my dose had been increased. For no reason at all, I'm to be moved to another ward, for no reason at all. (...). It's really taken its toll on me, being in hospital. I've been in lots of wards and been moved around a lot. (...) It's much better now (under $O C)$ when I have clearer agreements and regular people. It's not just suddenly changing doctors, or changing what's going to happen."
}

Stability of treatment was seen as beneficial by many, providing a secure framework for help close at hand when needed. Patients under an OC also seem to enjoy an increased flexibility in that services are better adapted to individual needs than previously, enabling the participants to feel more influence and less coercion than during hospitalisation. A typical feature of the stories is that individual needs are now taken seriously and decisions take place on the participants' own terms, as Tone described:

\footnotetext{
"When you're on an OC you don't have to go via the emergency service, you just go straight in. I did that last time. I took the initiative, I rang them and said I was having a hard time and needed to get in. They've made a new rule that even if you're on an $O C$, you can admit yourself voluntarily. (...) I think that's a very good idea, it's really great. I like it because then I could just say: "I'm discharging myself"! Before the doctor had to decide."
}

However, in spite of the positive aspects of increased freedom and influence, OC still represents continued contact with the institutions. Nobody reported concrete coercion under OC, but to understand the coercion in OC, we must recognise how it affects everyday life and restricts freedom of action and privacy. None of the participants actually wanted to be under $\mathrm{OC}$, and their stories typically reveal an institutional presence even though they were living at home. This involved the 
procedures and agreements of the $\mathrm{OC}$, such as continuous follow-up, visits and phone calls. Due to the administration of medication, keeping medical appointments, care and supervision in the home, the patients' privacy and everyday activities needed to be planned and adapted to the structures of the health care services. Nevertheless, they talked of extremely tight control with regard to medication. Marius told how he must report his plans and adapt his everyday life to when he got medicine at home:

"It'd been nice to have voluntary status, things had calmed down a bit then, all those phone calls. (...) There was a time they rang every day, every morning. (..) (and also) the medicine people come here every morning."

One's living room thus becomes an institution outside the institution, and the home an arena for the structure and implementation of the OC. One may perceive this as restrictions on one's social and private life. Knowing and feeling that others are controlling and observing them was described by the participants as stressful. Knowing that others decide about them and their treatment created uncertainty as to what might happen: would they again be forcibly hospitalised and medicated? Two participants reported living in constant fear of being readmitted.

Although the participants felt that OC was a freer system than hospitalisation, it also maintained their identity as a patient. It was for example difficult to go on holiday; Marius said that his mother would need to accompany him, as he was not allowed responsibility for self-medication.

\section{Obedience as a strategy}

The participants knew what could await them if they did not obey the clinician's requirements under $\mathrm{OC}$. They have learnt this from their experiences of specific types of coercion as inpatients and the way clinicians present the OC. Arne related in detail how coercion could be carried out within the OC framework if he did not obey:

\footnotetext{
"We've discussed the consequences, first someone from the hospital will come to your home, this was while I was on the depot injection, and ask if I'd like to come, but they don't have any authority to physically take you out of your house. But they would have contact with the police who in the next step, they are authorised to use force, physical force as a last resort to get you to take Zyprexa."
}

With this background knowledge, the participants chose to follow the scheme, seeming to accept its framework and content. This meant that clinicians did not need to enforce physical coercion because the patients obeyed the system that gave them the most freedom and the least violation of their autonomy. Kari told how she adapted to the OC on a daily basis and acted against her own will because she felt she had no real choice:

\footnotetext{
"I must do as they say, go to the doctor to get an injection, go to a psychiatrist to talk, go to a psychiatric nurse to talk. When I'm forced I feel it in my body, it's really tough. Just like tons of rocks being put on my back ... I get pressed down. (...) I have to live up to their expectations (...) the way I think they expect me to be."
} 
Kari's everyday life was powerfully affected by the stressful nature of her submission. Kari disagreed strongly with the treatment, but considered OC as a better alternative than hospitalisation. Her choice to live up to the clinicians' expectations was thus the less stressful option.

Their stories reveal clearly a lack of choice and autonomy under OC. The participants knew that compulsory medication would be the option if they did not obey. At the same time, they described a feeling of loyalty to the responsible clinician, leading to compliance in almost all cases. The participants' experience of not being taken seriously or listened to led to passivity. Although most experiences of not being seen, heard and taken seriously related to hospitalisation, the feeling of powerlessness continued under OC.

"It feels like I'm crying out for help, for someone to get me out of this, but no one can hear me. I'm all alone out in the woods. "(...)"I'm a dog sitting and panting and waiting for orders. That's how it feels, I'm so submissive that I'm just a dog." Kari

The participants said that they often found it difficult to imagine being allowed voluntary treatment. Nobody wanted to be under OC, given the choice, but a few said that their lives in practice would have been the same without OC. Others would reduce or break off contact with mental health services.

\section{Discussion}

\section{When coercion moves into your home}

When talking about OC, the participants' previous experience of involuntary hospitalisation was always the frame of reference (Fig. 1). Outpatient commitment was seen as more flexible and services were better adapted to individual needs, but their experiences of $\mathrm{OC}$ are still ambivalent. To understand coercion in the context of the de-institutionalised OC scheme, we must consider how control procedures and monitoring affect the patient's freedom of action and independence. The feeling of knowing that others make decisions on their behalf was experienced as stressful by almost all the participants. Lack of involvement in decision-making processes and the knowledge that others are in charge of them were felt to be the most intrusive factors. Although the participants were not subjected to concrete physical coercion, their stories indicate that they felt they were being coerced. Incoming phone calls and visits to the patients' flats by staff, which under normal circumstances usually are positive events, were perceived as invasive and such events were in many cases part of a control mechanism. Only one participant was subject to a forced medication order at the time of interview, yet many others were concerned about being medicated and found that they had little say in this matter.

The participants used their experiences of involuntary hospitalisation as a reference when they talked about OC. The impact of OC was always described on the basis of the desire to avoid involuntary hospitalisation. Moreover, the scheme gave them distinct advantages in that everyday life became more independent and predictable. 
In this perspective, life under OC was less burdensome and intrusive, and the participants experienced more privacy and freedom. There are similar findings from Sweden (Sjøstrøm 2012), New Zealand (Gibbs et al. 2005) and Canada (O`Reilly et al. 2006). Yet none of those interviewed in this study wanted to be under OC, as the control measures were experienced as negative, resulting in limited autonomy and freedom.

The most positive and most often emphasised aspects of $\mathrm{OC}$ were living at home, good access to assistance and stable treatment relationships. The value of these factors for patients is confirmed by other studies (O'Reilly et al. 2006, Gibbs et al. 2005). These factors are general prerequisites for good decentralised treatment (Lamb \& Bachrach 2001), and it may be questioned whether the coercion framework is necessary to provide satisfactory holistic health care. A study of patients with schizophrenia disorders showed that if patients are given the option to decide when they need help, the use of coercion can be significantly reduced (Heskestad \& Tytlandsvik 2008). In our study two participants found it helpful that they could choose voluntary hospitalisation while under OC.

When deciding whether to initiate or continue OC, the desired treatment outcome should be weighed against the burden experienced by the patient (Wertheimer 1993). In such an approach the decisive criterion should not only be that the patient will actually have a better life with an OC intervention but also that the services are administered with as few restrictions as possible (Szmukler \& Holloway 2000). Some of the study participants function at a level where many clinicians would consider OC the most realistic alternative to involuntary hospitalisation. Seen from this perspective, $\mathrm{OC}$ represents a more flexible solution for the most severely ill, offering greater privacy within controlled limits. The goal of applying the least intrusive measures is thus met where the only alternative to OC appears to be involuntary hospitalisation. However, this is problematic since it is difficult to demonstrate satisfactory treatment results in OC compared with voluntary aftercare (Churchill et al. 2007, Burns et al. 2013). The only coercive measure under the scheme (forced recall to hospital) has not been necessary in any of the included cases.

Nevertheless, the participants complied with the OC order because the alternative would have implied a greater restriction of their freedom. They were well aware of their legal status and the possible consequences of non-compliance with the scheme, and therefore chose to obey the rules. Outpatient commitment has been described as "persuading the persuadable" (Pinfold et al. 2001, Dawson \& Mullen 2008) where threats of readmission can be used to achieve treatment compliance outside the hospital. It is therefore quite conceivable that any opposition to control is undercommunicated for fear of more coercion. This may indicate that the participants sometimes act against their own will because they feel that to do otherwise would result in less freedom of action. 
The participants' stories indicate how institutional routines moved into their homes. Staff working with patients on OC should be aware of this. It is of particular importance to note that interactions and interventions that under normal circumstances are perceived as non-coercive are perceived as coercive by the patients under an OC order. This is exacerbated by the fact that treatment and care take place in the patients' own homes. The restrictive measures taken to manage the care of the patients should be weighed against the necessity and proportionality of the restrictions imposed on the patients (Szmukler \& Holloway 2000).

\section{Limitations}

This study focused on patients' perspectives of OC. Subjective experience is referred to and evaluated based on the participant's own assessment of the situational changes. We intended to analyse general issues regarding the attitudes and experiences of patients concerning everyday life, coercion, treatment and services. We can never exclude the possibility that including more participants might offer new aspects. However, the main study findings apply to all participants, though the details or examples in the stories vary. Their stories also appeared as balanced and well-considered and concurred well with the contextual data. Based on our analysis and literature review, we therefore consider these stories, despite the limitations, to provide rich information. Although a limited sample will never be sufficient to permit a generalisation of findings to populations, it may be sufficient for valuable analytical generalisations that also other OC patients could recognise (Sandelowski 1995). The contextual data enables a comparison of the participants' stories with the actual events as described as others, but not to the extent of providing full ethnographical data of everyday life. Moreover, other elements would probably have been emphasised if the participants had been chosen from clinicians or family members of patients. User participation and further dialogue were considered as part of the protocol to develop the data; however, this could also have implied that participants with a lower level of functioning were excluded from participation.

\section{Conclusion and implications for practice}

A key finding in this study was that the participants generally complied with the OC requirements, since the alternative was involuntary hospitalisation, and also because of the clear and secure framework of OC. The study shows that the participants experienced coercion in OC differently from coercion in inpatient settings. None of the participants were subjected to concrete physical coercion. They also reported that the order gave them distinct benefits, like increased privacy, more independency and better quality of interaction with staff. Yet all of the participants felt coerced under the OC order. They perceived that their freedom of action was still restricted, and that they were subjected to various control measures. The lack of autonomy experienced generally refers to the discomfort of knowing that others have the power to decide on their behalf in areas of importance in their lives. Nevertheless, the patients complied with treatment and appointments with 
the treatment providers, because they regarded OC as their best option, even though none of them would wish to be under OC, given the choice.

Factors affecting patients' freedom of action under OC must be taken into account in work to reduce coercion and encourage its correct use in mental health care. Even where coercion is considered justified on the basis of clinical assessments, the principle of minimum harm should apply so that freedom of action is restricted as little as possible. Whether the patient will actually have a better life under the OC scheme should be the basis for assessment. This requires clinicians to focus on balancing a reduction in the patient's freedom against the effect of the treatment.

\section{Acknowledgements}

This study was funded by the Northern Norway Regional Health Authority, the University Hospital of North Norway and the University of Tromsø. We would like to thank the study participants for their willingness to share their stories and experiences, and all those involved in contacting the participants.

\section{References}

Beauchamp, T. L. \& Childress, J. F. (2009) Principles of biomedical ethics. 6th ed. Oxford: Oxford University Press, p. 99.

Burns, T. \& Dawson, J. (2009) Community treatment orders: how ethical without experimental evidence? Psychological Medicine 10, 1583-1586.

Burns, T., Rugkåsa, J., Molodynski, A., Dawson, J., Yeeles, K., Vazquez-Montes, M., Voysey, M., Sinclair, J. \& Priebe, S. (2013) Community treatment orders for patients with psychosis (OCTET): a randomised controlled trial. www.thelancet.com, Vol 381 Published online March 26, 2013 http://dx.doi.org/10.1016/S0140-6736(13)60107-5. Accessed: 2 April 2013.

Churchill, R., Owen, G., Hotopf, M. \& Singh, S. (2007) International experiences of using community treatment orders. London: Department of Health and Institute of Psychiatry, King's College London.

CQC (2011) Monitoring the Mental Health Act in 2010/11. The Care Quality Commission`s annual report on the exercise of its functions in keeping under review the operation of the Mental Health Act 1983. London: Care Quality Commission.

Council of Europe (22 September 2004) Recommendation Rec(2004)10 of the Committee of Ministers to member states concerning the protection of the human rights and dignity of persons with mental disorder. https://wcd.coe.int/ViewDoc.jsp?id=775685\&Site=CM. Accessed: 21 April 2013.

Dawson, J. \& Mullen, R. (2008) Insight and use of community treatment orders. Journal of Mental Health 17, (3), 269-80.

Frank, A. (2010) Letting Stories Breathe: A Socio-Narratology. Chicago: University of Chicago Press. 
Gibbs, A., Dawson, J., Ansley, C., \& Mullen, R. (2005) How patients in New Zealand view community treatment orders. Journal of Mental Health 14, (4), 357-368.

Heskestad, S. \& Tytlandsvik, M. (2008) Brukerstyrte kriseinnleggelser ved alvorlig psykisk lidelse (User-driven emergency admissions for serious mental illness). Tidsskriftet for den norske legeforening 128, 32-35.

Hoge, S. K., Lidz, C. W., Eisenberg, M. et al. (1997) Perceptions of Coercion in the Admission of Voluntary and Involuntary Psychiatric Patients. International Journal of Law and Psychiatry 20, 167181.

Høyer, G. \& Ferris, R. (2001) Outpatient Commitment. Some Reflections on Ideology, Practice and Implications for Research. Journal of Mental Health Law, 6, 56-65.

Iversen, K. I., Høyer, G. \& Sexton, H. C.(2007) Coercion and patient satisfaction on psychiatric acute wards. International Journal of Law and Psychiatry 30, 504-511.

Lamb, R. H. \& Bachrach, L. L. (2001) Some Perspectives on Deinstitutionalization. Psychiatric Services 52, 1039-45.

Lorem. G. (2008) Making sense of stories: the use of patient narratives within mental health care research. Nursing Philosophy 9, 62-71.

McKenna, B. G., Simpson, A. I. F. \& Laidlaw, T. M. (1999) Patient perceptions of coercion in mental hospital admission. International Journal of Law and Psychiatry 22, 143-153.

Mill, J. S. (1972) Utilitarianism, On Liberty, Considerations on Representative Government. London/Vermont: J.M. Dent \& Sons Ltd.

Mullen, R., Dawson, J. \& Gibbs, A. (2006) Dilemmas for clinicians in use of Community Treatment Orders. International Journal of Law \& Psychiatry 29, (6), 535-50.

Norwegian Department of Health and Social Affairs (1998) Om lov om etablering og gjennomføring av psykisk helsevern (psykiatriloven) (Act on the establishment and implementation of mental health care [the Mental Health Act]). Ot prp nr 11 (1998-99).

Norwegian Directorate of Health (2010) Bruk av tvang i psykisk helsevern for voksne i 2009 (The use of coercion in mental health care for adults in 2009). IS-1861.

http://helsedirektoratet.no/publikasjoner/bruk-av-tvang-i-psykisk-helsevern-for-voksne-i2009/Publikasjoner/bruk-av-tvang-i-psykisk-helsevern-for-voksne-i-2009.pdf Accessed: 8 April 2013.

Nyttingnes, O. \& Husum, T. L. (2011) Omfang, utvikling og geografisk variasjon i bruk av tvang i psykisk helsevern i Norge (The extent, development and geographical variation of the use of coercion in mental health care in Norway). Impuls tidskrift for psykologi 3, 20-32.

0`Reilly, R. L., Keegan, D. L., Corring, D., Shrikhande, S. \& Natarajan, N. (2006) A qualitative analysis of the use of community treatment orders in Saskatchewan. International Journal of Law and Psychiatry 29, 516-524.

Pinfold, V., Bindman, J., Thornicroft, G., Franklin, D. \& Hatfield, B. (2001) Persuading the persuadable: evaluating compulsory treatment in England using supervised discharge orders. Social Psychiatry and Psychiatric Epidemiology 36, 260-266. 
Raffard, S., D `Argembeau, A., Lardu, C.,Bayard, S., Beulenger, J. P. \& Linden, M. V. (2010) Narrative identity in schizophrenia. Consciousness and Cognition, 19: 328-340.

Ridley, J. \& Hunter, S. (2013) Subjective experiences of compulsory treatment from a qualitative study of early implementation of the Mental Health (Care\&Treatment) (Scotland) Act 2003. Health and social care in the community 21 (5), 5009-518.

Riessman, C. K. (2008) Narrative Methods for the Human Sciences. California: Sage Publications, Inc.

Rugkåsa, J. (2011) Compulsion in the community. An overview of legal regimes and current evidence. Impuls tidskrift for psykologi 3, 56-63.

Sandelowski, M. (1995) Focus on Qualitative Methods Sample Size in Qualitative Research. Research in Nursing \& Health 18, 179-1 83.

Sjøstrøm, S. (2012) Det diffusa tvånget. Patienters upplevelser av öppen tvångsvård (Diffuse coercion. Patient experiences of open coercive care). Socialstyrelsen 2012-1-35.

Swedish National Board of Health and Welfare (2009) En ny vårdform. En lägesrapport om öppen psykiatrisk tvångsvård och öppen rättspsykiatrisk vård (A new form of care. A status report on open compulsory psychiatric care and open forensic psychiatric care). Artikelnr 2009-126-149.

Szmukler, G. \& Holloway, F. (2000) Mental Health Law: Discrimination or Protection? Maudsley Discussion Paper No. 10. London: King`s College London.

Theodoridou, A., Schlatter, F., Ajdacic, V., Rössler, W., \& Jäger, M. (2012) Therapeutic relationship in the context of perceived coercion in a psychiatric population. Psychiatry Research, 200(2-3), 939944. doi: 10.1016/j.psychres.2012.04.012

Vitz, P. C. (1990) The Use of Stories in Moral Development: New Psychological Reasons for an Old Education Method. American Psychologist, 45, 709-20.

Wertheimer, A. (1993) A philosophical examination of coercion for mental health issues. Behavioral Sciences and the Law, 11, 239-258.

World Health Organization, Division of Mental Health and Prevention of Substance Abuse (1996) Mental Health Care Law: Ten Basic Principles. Geneva. 

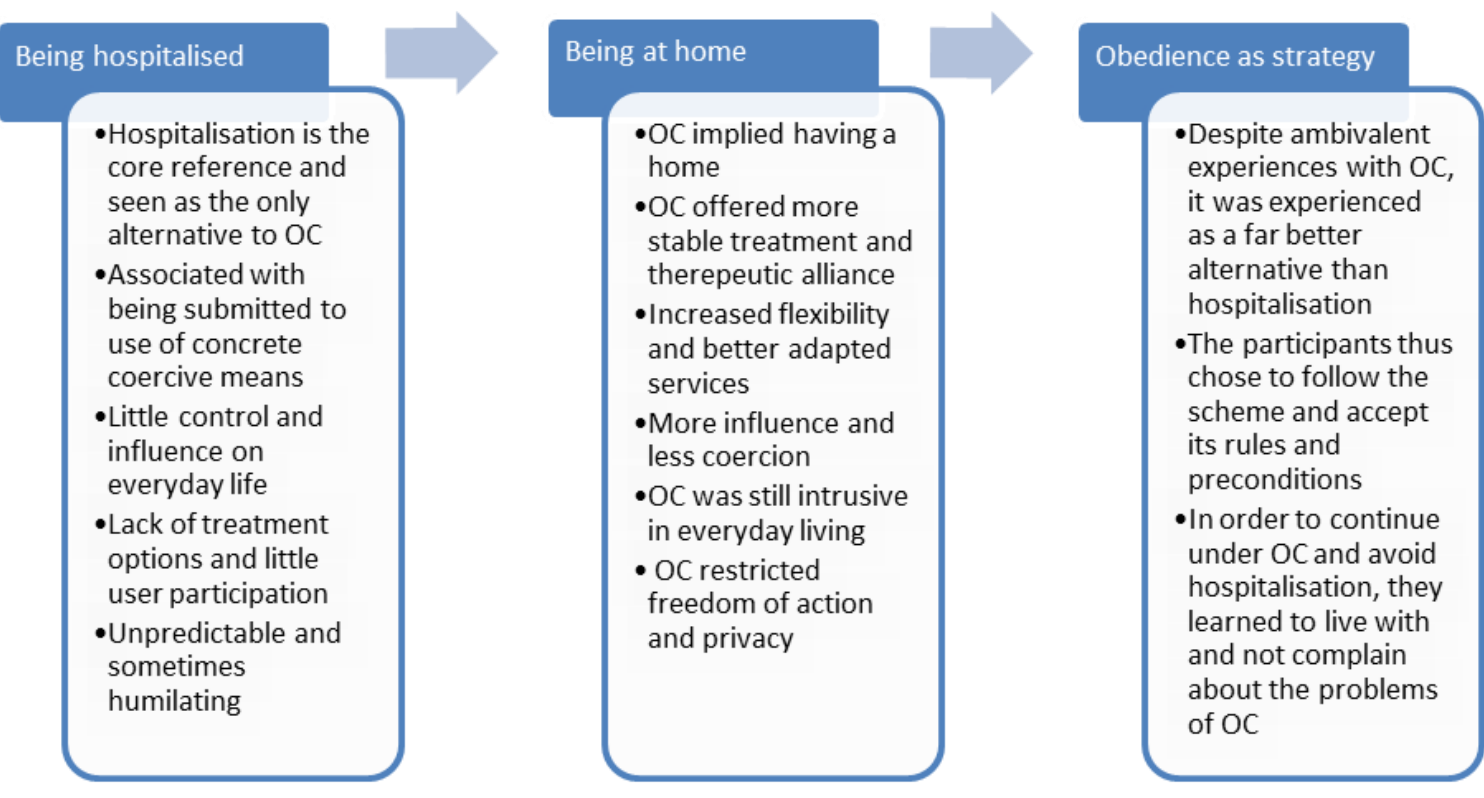

Figure 1 - Thematic Overview 